\title{
Synthetic immunostimulatory glycans interference with host cell apoptosis upon of Toxoplasma gondii infection, in vitro.
}

\author{
S.H. Eassa \\ Department of Anatomy, Histology and Biology, College of Medicine, Duhok University, Kurdistan Region, Iraq \\ Email: souzan.eassa@uod.ac
}

(Received April 7, 2017; Accepted May 9, 2017)

\begin{abstract}
Toxoplasmosis is a protozoan infection of humans and animals caused by Toxoplasma gondii, and it's continuous public health and food safety issue. The tachyzoites ( $\mathrm{Tg}$ ) of $T$. gondii are the most important stage, as they come in direct contact with immune cells such as a macrophage. Tg can modulate and prevent apoptosis of immune cells while promoting survival of the pathogen. Infections caused by $\mathrm{Tg}$ can be eradicated if immune cells could stimulate apoptosis and kill pathogens upon exposure. Apoptosis is characterized by the release of mediators, namely Caspases (Cas). New means are required for inducing apoptosis and enhance immunity in the infected host cell to control toxoplasmosis. The present study investigated whether Synthetic Immuno-stimulatory Glycans (SIGs) influence Cas and Nitric oxide (NO) release and led to Tg damage. Gal $\beta 1$ -

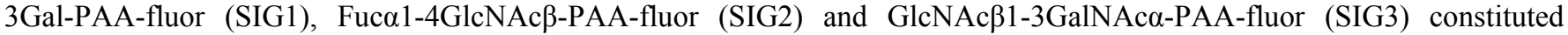
samples studied principally. Murine macrophage had been exposed to the Tg then the SIGs effects on Cas and NO production were determined after 20 hours of pathogen phagocytosis. Here we report that the SIGs had potent in vitro activity against $T$. gondii; SIG2 was more effective than SIG1 and SIG3, representative by SIG2 treated infected macrophages can induced infected macrophages to release Cas1, 3, and 9. Maximum production of NO by infected macrophages was noticed following the expoxure to all SIGs. Therefore the present study provided the method for the selection of SIGs ligands bearing immunostimulatory factor and apoptotic stimuli properties.
\end{abstract}

Keywords: T. gondii; caspases; apoptosis; nitric oxide Available online at http://www.vetmedmosul.org/ijvs

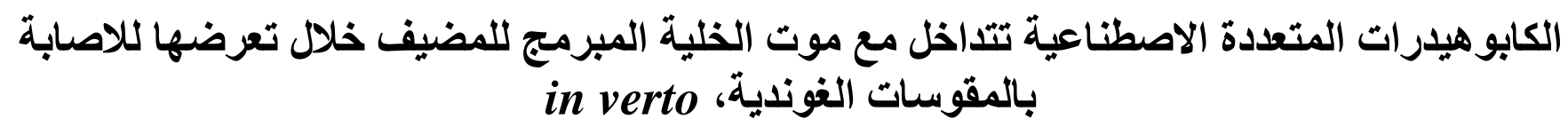

$$
\begin{aligned}
& \text { سوزان حسين عيسى } \\
& \text { قسم البايلوجي، كلية الطب، جامعة دهوك، اقليم كوردستان، العراق }
\end{aligned}
$$

داء المقوسات هو مرض يصيب الانسان و الحيو ان و المسبب هو طفيلي من الاو الي يطلق عليه اسم المقوسات الغوندية (Toxoplasma)

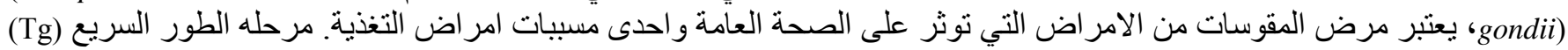

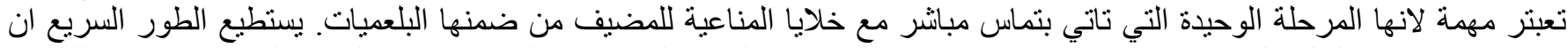

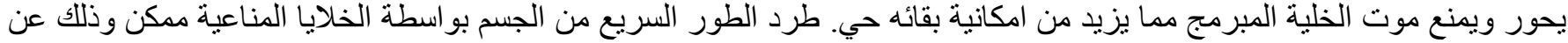

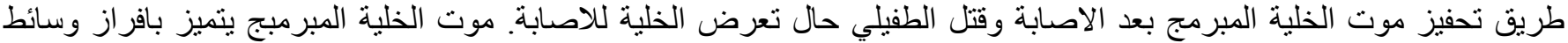

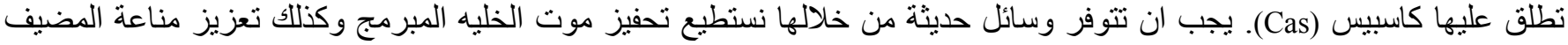

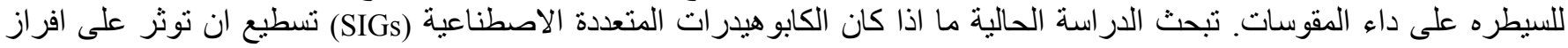

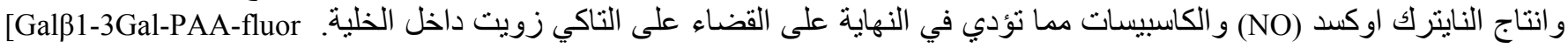




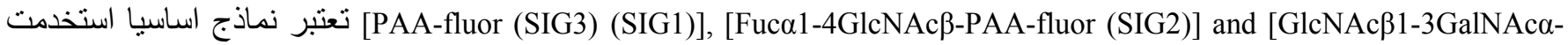

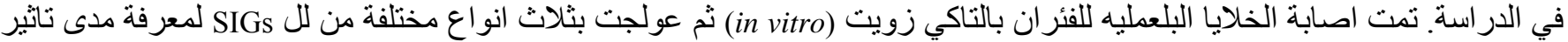

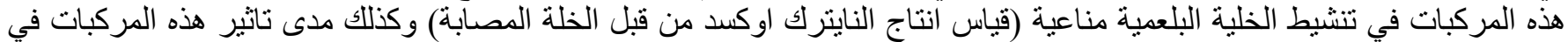

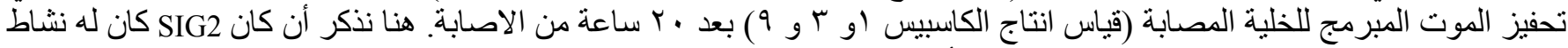

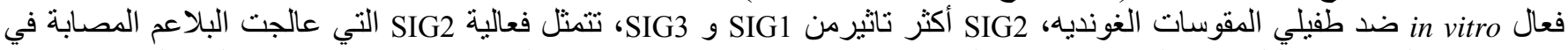

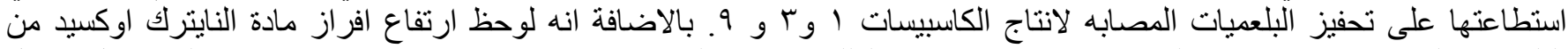

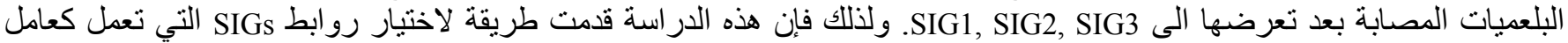

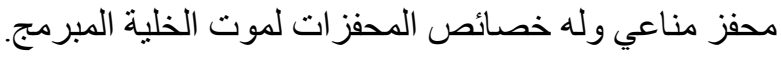

\section{Introduction}

T. gondii is a unique obligatory intracellular protozoan. It infects a variety of cells in almost all warm blooded animals which in turn causes toxoplasmosis, a disease with acute and chronic infections (1). Toxoplasmosis is a zoonotic disease can be transmitted from animal to humans, the individuals at risk for life-threatening toxoplasmosis's forms, such as encephalitis, myocarditis, and retinitis, include in immunocompromised patients, pregnant women and animals, and fetuses (2,3). Chemotherapy of toxoplasmosis is mandatory; however, available treatments are limited, side effects are common, and are effective against the tachyzoite stage only $(1,4)$. To date, there is no drug which is effective against chronic Toxoplasma infections and no licensed vaccine available for human $(5,6)$.

A class of cysteine proteases (Caspases) are synthesized as inactive preforms (i.e., zymogens) $(7,8)$. Triggering of (Cas) preludes the final commitment to death after cells have encountered intrinsic or extrinsic apoptotic promoter (9). Apoptosis has recently been recognized as an important defense system against viral, bacterial, and parasitic pathogens during innate and adaptive immune responses $(10,11)$. Although, it has been demonstrated that macrophages are essential immune cells of resistance and restrict parasite replication during toxoplasmosis $(12,13)$, but $\mathrm{Tg}$ have improved mechanisms to inhibit host cell apoptosis which helps Tg to survive and replicate (14), and macrophages under some conditions of Toxoplasma infection may act as Trojan horses to spread the $\mathrm{Tg}$ (15). Therefore, it is important to induce early apoptosis host cell upon $\mathrm{Tg}$ infection.

The production of nitric oxide (NO) by activated macrophages was recognized to be the primary antiparasitic effector mechanism $(16,17)$. There is good evidence that the macrophages infected with $T$. gondii are resistant to multiple inducers of apoptosis (18). Also previously reported that NO levels increased during toxoplasmosis $(17,19)$ and potentially induce apoptosis $(20$, 21 ) which decreased $T$. gondii replication $(17,19,22,23)$.
Carbohydrates bearing molecules (glycans or lectins) are pivotal in biological activities such as immunity, development, and phagocytosis (24), and they play a crucial role in biological communication between adjacent cells (25) and immune cells (26). Several of Tg receptors are natural carbohydrate-bearing molecules (27-29) which are important and allow the $\mathrm{Tg}$ to interact with responding to the external environment (30). Researchers investigated the ability of naturally occurring carbohydrates and synthetic carbohydrates to restrict or prevent $T$. gondii infection (31).

Synthetic Immuno-stimulatory Glycans (SIGs) are suitable ligands for the recognition and binding of pathogens (32). It was reported that SIGs selectively early recognize and bind to $\mathrm{Tg}$ (33). Also SIGs stimulate NO production and increase macrophage resistance during acute toxoplasmosis (34). In addition, Natural Carbohydrates or SIGs were reported to have a longer shelf live than proteins or antibodies, (35-37). Correspondingly using SIGs either in stimulation the individual immunity or treatment would provide a greater advantage over proteins both economically and regarding molecular stability (38). Thus, current study might produce promising candidates for SIGs which can influence and upregulate apoptosis of the infected macrophages and may be used for therapy against toxoplasmosis (39).

T. gondii tachyzoites type I (RH) strain, are highly virulent and they were used as a pathogen model in this research. The aim of this study was investigating whether SIGs influence Cas release by murine macrophage (M) after 20 hours of $\mathrm{Tg}$ in vitro phagocytosis and analyzing whether NO production is associated with Cas release.

\section{Materials and methods}

RH strain T. gondii tachyzoites, Dulbecco's modified eagle's medium (DMEM), Roswell Park Memorial Institute medium (RPMI) 1640, Dulbecco's phosphate buffered saline 1x (PBS), fetal bovine serum (FBS), penicillin $10,000 \mathrm{IU}$ and streptomycin $10,000 \mu \mathrm{g} / \mathrm{ml}$, trypsin-EDTA solution $(0.25 \%$ Trypsin $/ 0.53 \mathrm{mM}$ EDTA in Hanks Balanced Salt Solution without calcium or magnesium), Human foreskin fibroblasts (HFFs), and culture grade water 
were obtained from the American Type Culture Collection (ATCC) (Manassas, VA, USA). C57BL/6 female 6 to 8 weeks mice were purchased from Harlan Sprague Dawley, Inc. (Indianapolis, IN). Fluoresceinated disaccharide polymers Glyc-PAA-flu (SIG1, SIG2, and SIG3), was purchased from GlycoTech, Inc. (Rockville, MD). Caspase colorimetric assay kits were obtained from BioVision, Inc. (Linda Vista, CA, USA). Griess reagent $[0.1 \%(\mathrm{w} / \mathrm{v}) \mathrm{N}-(1$ naphthyl) ethylenediamine dihydrochloride and $1 \%(\mathrm{w} / \mathrm{v})$ sulfanilamide in $5 \%(\mathrm{v} / \mathrm{v})$ phosphoric acid] were purchased from Sigma Chemical Co. (St Louis, MO, USA).

\section{T. gondii propagation and purification}

T. gondii RH strain ( $\mathrm{Tg}$ ) was maintained as tachyzoites by serial passage on monolayers of HFFs at $37^{\circ} \mathrm{C}$ with $5 \%$ $\mathrm{CO}_{2}$ in Dulbecco's modified Eagle's medium (DMEM) supplemented with $10 \%$ fetal bovine serum, $1 \%$ penicillinstreptomycin. The viability of the parasites was determined by trypan blue (40).

\section{Isolation of murine peritoneal cavity macrophages}

C57BL/6 mice were injected intraperitoneally with 1.5 $\mathrm{ml}$ of $3 \%$ Thioglycolate broth. Five days after injection, mice were euthanized, and peritoneal exudate cells were collected by lavage with $5.0 \mathrm{ml}$ RPMI 1640. Peritoneal macrophages were plated at $1.2 \times 10^{6}$ cells/ well in 6-well culture plate then incubated at $37^{\circ} \mathrm{C}$ in $5 \% \mathrm{CO}_{2}$ for 2 hours. Non-adherent cells were removed by washing with fresh RPMI 1640 media without antibiotics. Macrophages were infected at a tachyzoites-to-cells ratio of $2: 3\left(8 \times 10^{5}\right.$ tachyzoites/ $1.2 \times 10^{6}$ cell). Each well was immediately treated with $0.03 \mu \mathrm{g}$ of SIGs and incubated for 20 hours at $37^{0} \mathrm{C}$ in $5 \% \mathrm{CO}_{2}$. Cas and $\mathrm{NO}$ productions were determined on (1) macrophages treated with SIG (M+SIG); (2) macrophages exposed to either tachyzoites only $(\mathrm{M}+\mathrm{Tg})$ or (3) macrophages treated with SIG after tachyzoites exposure $(\mathrm{M}+\mathrm{SIG}+\mathrm{Tg})$ and comparing those conditions to untreated macrophages ( $\mathrm{M}$ only).

\section{In vitro nitric oxide (NO) analysis}

SIGs effect on macrophages activation was investigated by determining nitric oxide production 20 hours after infection or post phagocytosis. Culture supernatants (100 $\mu \mathrm{l})$ were assayed for nitric oxide determination using the Griess assay. The nitrite ion (NO2-) concentration, indicative of $\mathrm{NO}$, was determined using $\mathrm{NaNO}_{2}$ as a standard (41). The cell culture supernatant $(100 \mu \mathrm{l})$ was mixed with an equal volume of Griess reagent $[0.1 \%(\mathrm{w} / \mathrm{v})$ $N$-(1 naphthyl) ethylenediamine dihydrochloride and $1 \%$ $(\mathrm{w} / \mathrm{v})$ sulfanilamide in $5 \%(\mathrm{v} / \mathrm{v})$ phosphoric acid]. The samples were incubated at room temperature for 20 minutes, and absorbance was measured at $490 \mathrm{~nm}$ using a Bio-Tek Ex800 plate reader.

\section{In vitro Caspases activities}

The caspase proteolytic activity in lysates macrophages was determined with Caspases 1, 3, and 9 Colorimetric Assay Kits. Cas peptides were obtained from the postphagocytosis studies of macrophages exposed to Tg. Cas peptides isolation was performed according to manufacturer protocol (BioVision Research Products). Briefly, after 20 hours of incubation, the macrophages were harvested and resuspended in $50 \mu \mathrm{l}$ of chilled cell lysis buffer. Isolated cells were incubated on ice for $10 \mathrm{~min}$ followed by centrifugation of the suspension for $1 \mathrm{~min}$ in a microcentrifuge $(10,000 \mathrm{x} \mathrm{g})$. Finally, the supernatant (or cytosolic extract) was transferred to a fresh tube and kept on ice for further assay.

Cas peptides were determined based on spectrophotometric detection of the cleavaged chromophore p-nitroanilide ( $p N A)$ from the labeled substrate Cas- $p$ NA sequences including YVAD, DEVD, and LEHD according to the company protocol (reference from the biovesion company). Above amino acid sequences allow detecting Cas 1, 3, and 9 respectively. The cytosolic extract was diluted to concentrations $50-200 \mu \mathrm{g}$ protein using $50 \mu \mathrm{l}$ cell lysis buffer and plated into each well of a 96-wells plate. Soon after, $50 \mu \mathrm{l}$ of $2 \times$ reaction buffer $(10 \mu \mathrm{M}$ DTT) was added to each sample. Then, $5 \mu \mathrm{l}$ of the $4 \mathrm{mM}$ Cas-pNA substrate $(200 \mu \mathrm{M}$ final concentration) was introduced, and plates were incubated at $37^{\circ} \mathrm{C}$ for 2 hours protected from light. After incubation, samples were read at $405-\mathrm{nm}$ using a Bio-Tek Ex800 plate reader.

\section{Statistical analysis}

SAS ${ }^{\circledR}$ statistics software was used for all statistical analysis. The data represents the mean of three wells per experimental group and results were accepted as statistically significant at $p$-values $<0.05$ using Student's $t$ test and ANOVA. The Tukey test was performed for post ANOVA to indicate which group was not statistically significant compared to the others.

\section{Results and discussion}

The current research aims to gain deeper insight into whether SIGs could make macrophages capable of undergoing early apoptosis on $T$. gondii tachyzoites exposure, by controlling Cas cascade and associated with NO releasing.

NO is a radical with a small molecular weight released by immune cells like macrophages. We studied the effect of SIG1, SIG2, and SIG3 on NO production by macrophages infected with $\mathrm{Tg}$ (Figure 1). SIGs alone activate macrophages and increase NO release. The NO release by untreated macrophages ( $\mathrm{M}$ only) was considered as the baseline of NO release and compared with both, T. gondii 
treated sample $(\mathrm{M}+\mathrm{Tg})$ and SIGs treated sample $(\mathrm{M}+\mathrm{SIG1-}$ 3), while $\mathrm{M}$ only, $\mathrm{M}+\mathrm{Tg}$, and $\mathrm{M}+\mathrm{SIG1-3}$ were used as controls.

Exposure of macrophages to SIGs alone (M+SIG1, $\mathrm{M}+\mathrm{SIG} 2$, and $\mathrm{M}+\mathrm{SIG} 3$ ) activate macrophages and increase NO release. When we were statistically comparing $\mathrm{M}+\mathrm{SIG} 1, \mathrm{M}+\mathrm{SIG} 2$, and $\mathrm{M}+\mathrm{SIG} 3$ to $\mathrm{M}$ and $\mathrm{M}+\mathrm{Tg}$, the results showed significant differences $(P<0.05)$ in the expression of NO production. Conversely, there were no significant differences among $\mathrm{M}+\mathrm{SIG} 1, \mathrm{M}+\mathrm{SIG} 2$, and $\mathrm{M}+\mathrm{SIG} 3$; they all showed a similar pattern of NO release. This result is in agreement with those of Lahiani (42).

Recent results indicated that murine macrophages slightly increase NO production after 20 hours of $\mathrm{Tg}$ infection, as it was shown in other previous work (43). In addition, our results showed that after 20 hours of $\mathrm{Tg}$ infection the SIG-treated macrophages $(\mathrm{M}+\mathrm{SIG} 1+\mathrm{Tg})$, $(\mathrm{M}+\mathrm{SIG} 2+\mathrm{Tg})$, and $(\mathrm{M}+\mathrm{SIG} 3+\mathrm{Tg})$ displayed significantly higher NO production $\left({ }^{*} P<0.05\right)$ compared with $\mathrm{M}+\mathrm{Tg}$ and M+SIG1-3. Macrophages treated with SIG2 $(\mathrm{M}+\mathrm{SIG} 2+\mathrm{Tg})$ released a high level of $\mathrm{NO}(1830.16 \mu \mathrm{M} / \mathrm{ml})$ upon exposure to the tachyzoites $\mathrm{M}+\mathrm{SIG} 2+\mathrm{Tg}$ compared to $\mathrm{M}+\mathrm{SIG} 1+\mathrm{Tg}$ and $\mathrm{M}+\mathrm{SIG} 3+\mathrm{Tg}\left({ }^{*} P<0 \cdot 05\right)$.

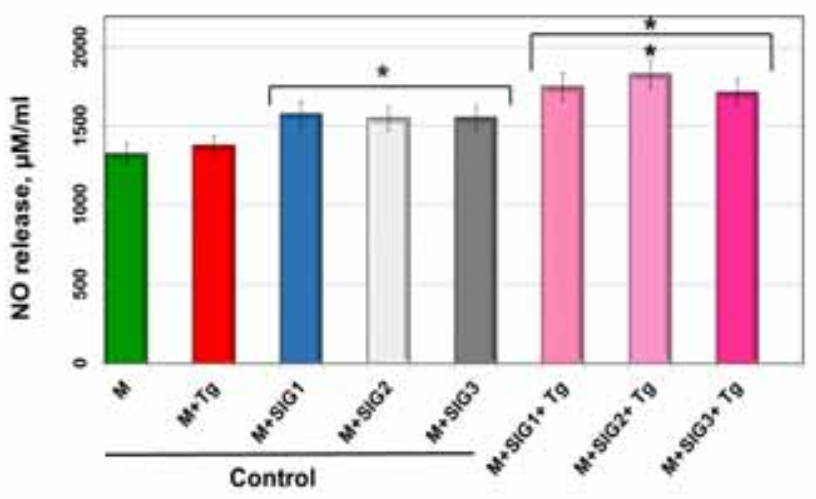

Figure 1: Nitric oxide (NO) production as a function of 20 hours of post-phagocytosis.

After 20 hours, NO release by murine macrophages during tachyzoite infection was measured. Positive control results represent macrophages that were exposed to tachyzoites $(\mathrm{M}+\mathrm{Tg})$ and $\mathrm{NO}$ release by untreated macrophages (M) was considered as the baseline of NO release and compared to macrophages exposed to the tachyzoites $(\mathrm{M}+\mathrm{Tg})$. Macrophages during tachyzoites infection treated with SIG1, SIG2, or SIG3 $(\mathrm{M}+\mathrm{SIG} 1+\mathrm{Tg}$, $\mathrm{M}+\mathrm{SIG} 2+\mathrm{Tg}$, and $\mathrm{M}+\mathrm{SIG} 3+\mathrm{Tg}$ ) represented significant statistical difference compared to $(\mathrm{M}+\mathrm{Tg}),{ }^{*} p<0.05$. These results are the mean values of the NO production \pm the $\mathrm{SD}$ of three independent experiments and analyzed by ANOVA.
Released NO is an indication of the activation of macrophages in killing protozoa (44), and triggers the apoptotic pathway to induce macrophages death (45). Our present study has shown that NO production increased affectedly in early phagocytosis when the infected macrophages were treated with SIGs after 20 hours of Tg in vitro infection. We believe these findings represent the ability of NO production in stimulating Cas cascade which are very important in inducing early apoptosis of infected macrophages in order to combat $\mathrm{Tg}$ or to limit the $\mathrm{Tg}$ multiplication.

A hierarchy of caspases were determined the cell apoptotic pathway, that are classified into groups by their role as initiator Cas (e.g. caspases-2, -8 , and -9 in mice) cleave and stimulate the executioner Cas (e.g. caspases -3 , 6 and -7 ) and the inflammatory mediators Cas (caspase-1) $(46,47)$.

The cells apoptotic process commenced by a cascade that involves the activation of initiators and executioner caspases $(7,8)$. Additional steps drive to cleavage or stimulation of molecules bring about most of the morphological and biochemical characteristics of cell death, activate Cas 1 inflammatory mediators $(48,49)$ and eradicate the unwanted cells (old, cancer, and infected cells) from healthy individual bodies $(50,51)$.

It has been reported that $T$. gondii activates the host survival response, thereby increasing the overall resistance of infected cells to apoptotic stimuli (52). The effect of SIGs on Cas production by macrophage (M) upon $\mathrm{Tg}$ exposure after 20 hours of phagocytosis were studied. Present result has shown that macrophages only (M) demonstrated low level of Cas release as shown in Figure 2. While macrophages infected with tachyzoites $(\mathrm{M}+\mathrm{Tg})$ increased the levels of Cas1, 3, and 9 (3 and 4-fold above the $\mathrm{M}$ only at 20 hours of infection).

SIGs- treated macrophages (M+SIGs) and SIGs- treated macrophages during tachyzoites infection $(\mathrm{M}+\mathrm{SIGs}+\mathrm{Tg})$ were compared to untreated macrophage $M$ and $(M+T g)$. Releasing of Cas 1, 3 and 9 were significantly increased $\left({ }^{*} P<0.05\right)$ by the addition of SIG2 $(\mathrm{M}+\mathrm{SIG} 2)$ and $(\mathrm{M}+\mathrm{SIG} 2+\mathrm{Tg})$. On the contrast untreated macrophages $\mathrm{M}$ and macrophages exposed to SIG1 and SIG3 $(\mathrm{M}+\mathrm{SIG} 1$, $\mathrm{M}+\mathrm{SIG} 3, \mathrm{M}+\mathrm{SIG} 1+\mathrm{Tg}$, and $\mathrm{M}+\mathrm{SIG} 3+\mathrm{Tg}$ ) all represented low level of Cas 1, 3 and 9 on compared to $\mathrm{M}+\mathrm{Tg}$.

Consequently, further studies will be needed for assessing the effect of SIG1 and SIG3 on Cas production within timeframe of $T$. gondii infection. Also, the level of Cas that released by the infected cells $\mathrm{M}+\mathrm{Tg}$ should compared to the level of Cas that released by the uninfected $\mathrm{M}$ and infected cells $\mathrm{M}+\mathrm{Tg}$ during exposure to apoptotic stimuli such as TNFa. 


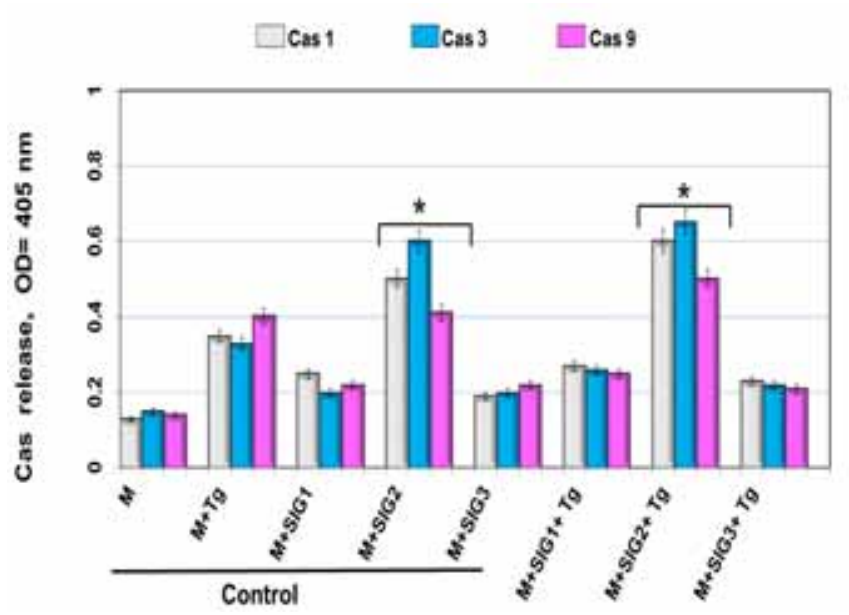

Figure 2: Caspases (Cas) production as a function of 20 hours of post-phagocytosis.

After 20 hours, Cas (1, 3, and 9) release by murine macrophages during tachyzoite infection was measured. Positive control results represent macrophages that were exposed to tachyzoites $(\mathrm{M}+\mathrm{Tg})$ and Cas release by untreated macrophages $(\mathrm{M})$ was considered as the baseline of Cas release and compared to macrophages exposed to the tachyzoites $(\mathrm{M}+\mathrm{Tg})$. In compare to $(\mathrm{M}+\mathrm{Tg}), \mathrm{SIG} 2$ increase Cas 1,3 , and 9 release by cell (M) after 20 hours of treated with SIG2 (M+SIG2) * $p<0.05$, and increase Cas 1, 3, and 9 release by cell (M) after 20 hours of exposure to $\mathrm{Tg}$ simultaneously treated with SIG2 $(\mathrm{M}+\mathrm{SIG} 2+\mathrm{Tg}) * p<0.005$. Error bars represent the standard deviation for the means from three independent experiments conducted in triplicate and analyzed by ANOVA.

Since Cas release by macrophages is used as an indicator of cell apoptosis, the inducing effects of SIG2 on macrophages and increase the level of Cas production that may contribute to the parasites ability to inhibit host cell apoptosis (53).

Previous studies have shown that $T$. gondii downregulates in vitro induced apoptosis by downregulates activation of caspases 3 and $9(54,14)$. In agreement with present results which showed that the level of 3 and 9 reduced, therefore we proposed that SIGs can activated Cas cascade during early Tg infection and induced macrophages apoptosis lead to block the $\mathrm{Tg}$ reproduction.

Figure 1 confirmed that NO production was increased after treatment of $T$. gondii infected with SIG2 $(\mathrm{M}+\mathrm{SIG} 2+\mathrm{Tg})$, the data adds evidence for a role of $\mathrm{NO}$ in Cas 1, 3, and 9 production and the induction of apoptosis. This results agree with research done by Nishikawa team (55).

Depend on achieved results, in vitro mechanism action of SIG influence on NO and caspase Cas production after
20 hours phagocytosis was suggested. SIG present will bind either to cell (M) or pathogen (Tg). This make the Tg more prone to engulfed by macrophages lead to stimulate early immune defense and cell apoptosis by induce $\mathrm{NO}$ and Cas release (Figure 3).

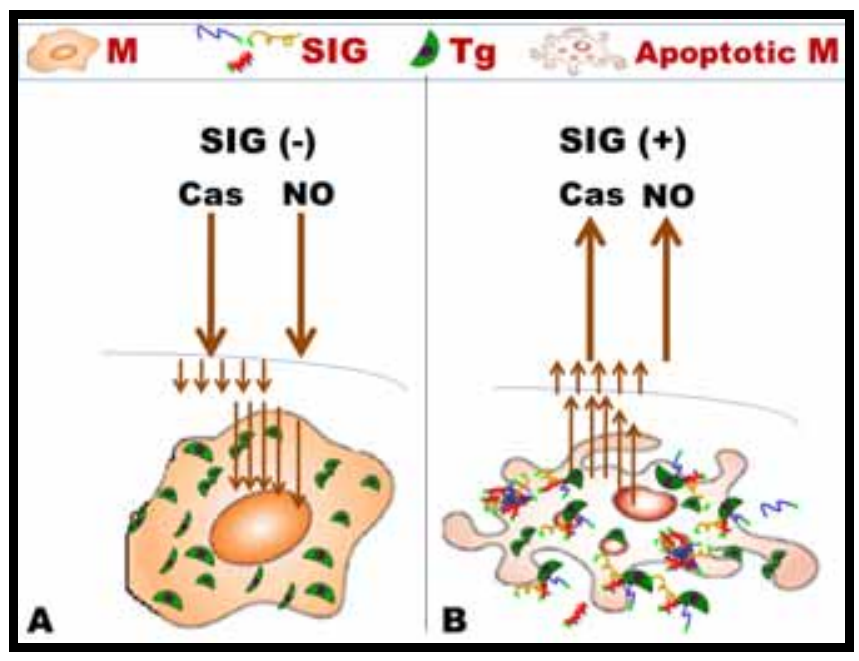

Figure 3: The suggested in vitro mechanism action of Synthetic immunostimulatory Glycans (SIG) influence on Nitric oxide (NO) and caspase (Cas) production.

A- Tachyzoites (Tg) actively attack non-treated macrophage (M) leading to partial inhibition of NO release and Cas production, thus prevent apoptosis and increase the chance of Tg replication. B- Supposedly, Tg are engulfed by macrophages that are treated with SIG will cause rise of NO and Cas production which in turn result in early apoptosis of macrophages (Apoptotic M).

\section{Conclusion}

Inhibition of host cell apoptosis by $T$. gondii is accompanied by reduced activation of the caspase cascade. Present results demonstrated that the SIG2 have a pivotal role in the increasing $\mathrm{NO}$ and Cas production which ultimately lead to induce the apoptosis of infected macrophages. Taken together, our data show that SIGs can used as immunostimulatory influence which enhance the infected macrophage NO response against $\mathrm{Tg}$ infection. In addition, SIG2 was more effective than SIG1, and SIG3 after 20 hours of phagocytosis. SIG2 might use as stimulatory factor for inducing the infected cell during $\mathrm{Tg}$ infection and controls $\mathrm{Tg}$ replication. Therefore the present study provided the method for the selection of SIGs ligands bearing immunostimulatory factor and apoptotic stimuli properties. 


\section{Acknowledgments}

The research was supported by Ministry of Higher Education and Scientific Research of the Republic of Iraq, a grant (250029). The research was conducted at University of Arkansas at Little Rock, Departments of Biology and Applied Sciences. I would like to thank Dr. Lee Soderberg, Professor of Microbiology \& Immunology/ University of Arkansas for Medical Sciences, Dr. Nawab Ali, and Dr. Olga Tarasenko Associate Professor of Applied Sciences/ University of Arkansas at Little Rock for providing me access to biosafety level two Lab. This study conforms to the UALR's IBC 12-016 and UAMS's IBC protocol, the UALR's IACUC 0903 and the UAMS's AUP protocol 2985.

\section{References}

1. Montoya JG, Liesenfeld O. Toxoplasmosis. Lancet. 2004;363(9425):1965-76.

2. Paquet $\mathrm{C}$, Yudin MH, Society of Obstetricians and Gynaecologists of Canada. Toxoplasmosis in pregnancy: prevention, screening, and treatment. J Obstet Gynaecol Can. 2013;35(1):78-81.

3. McAllister MM. A decade of discoveries in veterinary protozoology changes our concept of "subclinical" toxoplasmosis. Vet Parasitol. 2005;132(3-4):241-7.

4. Meneceur P, Bouldouyre MA, Aubert D, Villena I, Menotti J, Sauvage V, et al. In vitro susceptibility of various genotypic strains of Toxoplasma gondii to pyrimethamine, sulfadiazine, and atovaquone. Antimicrob Agents Chemother. 2008;52(4):1269-77.

5. Liu Q, Singla LD, Zhou H. Vaccines against Toxoplasma gondii: status, challenges and future directions. Hum Vaccin Immunother. 2012;8(9):1305-8.

6. Khryanin AA, Reshetnikov OV, Kuvshinova IN. Toxoplasmosis: Epidemiology, Diagnosis, Treatment. Antibiot Khimioter. 2015;60(56):16-21.

7. Thornberry NA, Lazebnik Y. Caspases: enemies within. Science. 1998;281(5381):1312-6.

8. Strasser A, O'Connor L, Dixit VM. Apoptosis signaling. Annu Rev Biochem. 2000;69:217-45.

9. Luder CG, Walter W, Beuerle B, Maeurer MJ, Gross U. Toxoplasma gondii down-regulates $\mathrm{MHC}$ class II gene expression and antigen presentation by murine macrophages via interference with nuclear translocation of STAT1alpha. Eur J Immunol. 2001;31(5):1475-84.

10. Liles WC. Apoptosis - role in infection and inflammation. Curr Opin Infec Dis. 1997;10:165-170.

11. Williams GT. Programmed cell death: a fundamental protective response to pathogens. Trends Microbiol. 1994;2(12):463-4.

12. Murray HW, Juangbhanich CW, Nathan CF, Cohn ZA. Macrophage oxygen-dependent antimicrobial activity. II. The role of oxygen intermediates. J Exp Med. 1979;150(4):950-64.

13. Masek SK, Hunter AC. Pro-Inflammatory Responses in Macrophages during Toxoplasma gondii Infection. In: Denker EY, Grazzinelli RT, Editors. Protozoan in Macrophages. Texas: Landes Bioscience; 2007. P. 1-237.

14. Goebel S, Gross U, Luder CG. Inhibition of host cell apoptosis by Toxoplasma gondii is accompanied by reduced activation of the caspase cascade and alterations of poly(ADP-ribose) polymerase expression. J Cell Sci. 2001;114(Pt 19):3495-505.

15. Butcher BA, Kim L, Johnson PF, Denkers EY. Toxoplasma gondii tachyzoites inhibit proinflammatory cytokine induction in infected macrophages by preventing nuclear translocation of the transcription factor NF-kappa B. J Immunol. 2001;167(4):2193-201.
16. Rozenfeld C, Martinez R, Figueiredo RT, Bozza MT, Lima FR, Pires $\mathrm{AL}$, et al. Soluble factors released by Toxoplasma gondii-infected astrocytes down-modulate nitric oxide production by gamma interferon-activated microglia and prevent neuronal degeneration. Infect Immun. 2003;71(4):2047-57.

17. Daubener $\mathrm{W}$, Posdziech V, Hadding U, MacKenzie CR. Inducible anti-parasitic effector mechanisms in human uroepithelial cells: tryptophan degradation vs. NO production. Med Microbiol Immunol. 1999;187(3):143-7.

18. Nash PB, Purner MB, Leon RP, Clarke P, Duke RC, Curiel TJ. Toxoplasma gondii-infected cells are resistant to multiple inducers of apoptosis. J Immunol. 1998;160(4):1824-30.

19. Kang KM, Lee GS, Lee JH, Choi IW, Shin DW, Lee YH. Effects of iNOS inhibitor on IFN-gamma production and apoptosis of splenocytes in genetically different strains of mice infected with Toxoplasma gondii. Korean J Parasitol. 2004;42(4):175-83.

20. Candolfi E, Villard O, Thouvenin M, Kien TT. Role of nitric oxideinduced immune suppression in toxoplasmosis during pregnancy and in infection by a virulent strain of Toxoplasma gondii. Curr Top Microbiol Immunol. 1996;219:141-54.

21. Candolfi E, Hunter CA, Remington JS. Mitogen- and antigen-specific proliferation of $\mathrm{T}$ cells in murine toxoplasmosis is inhibited by reactive nitrogen intermediates. Infect Immun. 1994;62(5):1995-2001.

22. Adams LB, Hibbs JB,Jr, Taintor RR, Krahenbuhl JL. Microbiostatic effect of murine-activated macrophages for Toxoplasma gondii. Role for synthesis of inorganic nitrogen oxides from L-arginine. J Immunol. 1990;144(7):2725-9.

23. Karaman U, Celik T, Kiran TR, Colak C, Daldal NU. Malondialdehyde, glutathione, and nitric oxide levels in Toxoplasma gondii seropositive patients. Korean J Parasitol. 2008;46(4):293-5.

24. Merry AH, Merry CL. Glycoscience finally comes of age. EMBO Rep. 2005;6(10):900-3.

25. Liang $\mathrm{PH}, \mathrm{Wu} \mathrm{CY}$, Greenberg WA, Wong $\mathrm{CH}$. Glycan arrays: biological and medical applications. Curr Opin Chem Biol. 2008;12(1):86-92.

26. Gabius HJ,. The Sugar Code: Fundamentals of Glycosciences. $1^{\text {st }}$ ed. Wiley-VCH Verlag GmbH \& Company; 2009. 597 p.

27. Odenthal-Schnittler M., Tomavo S, Becker D, Dubremetz JF, Schwarz RT. Evidence for N-linked glycosylation in Toxoplasma gondii. J Biochemistry. 1993; 2919 (Pt 3):713-721.

28. Zinecker CF, Striepen B, Tomavo S, Dubremetz JF, Schwarz RT. The dense granule antigen, GRA2 of Toxoplasma gondii is a glycoprotein containing O-linked oligosaccharides. Mol Biochem Parasitol. 1998;97 (1-2):241-6.

29. McConville MJ, Ferguson MA. The structure, biosynthesis and function of glycosylated phosphatidylinositols in the parasitic protozoa and higher eukaryotes. Biochem J. 1993;294( Pt 2)(Pt 2):305-24.

30. Guha-Niyogi A, Sullivan DR, Turco SJ. Glycoconjugate structures of parasitic protozoa. Glycobiology. 2001;11(4):45R-59R.

31. Tsai YH, Gotze S, Azzouz N, Hahm HS, Seeberger PH, Varon Silva D. A general method for synthesis of GPI anchors illustrated by the total synthesis of the low-molecular-weight antigen from Toxoplasma gondii. Angew Chem Int Ed Engl. 2011;50(42):9961-4.

32. Tarasenko O, Islam S, Paquiot D, Levon K. Glycoconjugates for the recognition of Bacillus spores. Carbohydr Res. 2004;339(18):2859-70.

33. Eassa SH, Bose Ch, Alusta P, Tarasenko O, Detection Method of Toxoplasma gondii Tachyzoites. American Institute of Physics. 2011;132:157-165.

34. Eassa SH, Soderberg LS, Lahiani M, Pavan C, Tarasenko O. Synthetic Carbohydrate-based Polymers Increased Macrophage Resistancy during Toxoplasma gondii Infection. Polymeric Materials: Science \& Engineering. 2012; 106-267.

35. Axford J. The impact of glycobiology on medicine. Trends Immunol. 2001;22(5):237-9.

36. Borman S, Carbohydrate vaccines. Chem. Eng. News. 2004;82(32): 31-34. 
37. Bertozzi CR, Kiessling LL. Chemical glycobiology. Science. 2001;23;291(5512):2357-64

38. Kiessling LL, Pohl NL. Strength in numbers: non-natural polyvalent carbohydrate derivatives. Chem Biol. 1996;3(2):71-7.

39. Koolen MJM, Damm JBL, Striepen B, Schwarz RT. Toxoplasma gondii Glycoconjugates, United States Patent Application 95202500.5 (20020058288). 2002:1-3.

40. Chang HR, Comte R, Pechere, JC, In vitro and in vivo effects of doxycycline on Toxoplasma gondii. Antimicrob Agents Chemother. 1990;34(5):775-780.

41. Keller R, Geiges M, Keist R. L-arginine-dependent reactive nitrogen intermediates as mediators of tumor cell killing by activated macrophages. Cancer Res. 1990;50(5):1421-5.

42. Lahiani, MH. Glycoconjugates Prevent Bacterial Dissemination and Cellular Death during B. Cereus/ B. Anthracis Infection [Master in Biology]. Little Rock (AR): University of Arkansas at Little Rock; 2012:1-194p.

43. Eassa SH, Soderberg LS. Stimulatory Effect of Synthetic Carbohydrate-Bearing Molecules on Nitric Oxide Production and Enhancing Macrophages Viability upon Exposure of $T$. gondii. Int'1 J Advances Chemical Eng Biol Sci. 2015;2(2):85-90.

44. Achike FI, Kwan CY. Nitric oxide, human diseases and the herbal products that affect the nitric oxide signalling pathway. Clin Exp Pharmacol Physiol. 2003;30(9):605-15.

45. Snyder CM, Shroff EH, Liu J, Chandel NS. Nitric oxide induces cell death by regulating anti-apoptotic BCL-2 family members. PLoS One. 2009;4(9):e7059.

46. Earnshaw WC, Martins LM, Kaufmann SH. Mammalian caspases: structure, activation, substrates, and functions during apoptosis. Annu Rev Biochem. 1999;68:383-424.
47. Boatright KM, Salvesen GS. Mechanisms of caspase activation. Curr Opin Cell Biol. 2003;15(6):725-31.

48. Boatright KM, Renatus M, Scott FL, Sperandio S, Shin H, Pedersen IM, et al. A unified model for apical caspase activation. Mol Cell. 2003;11(2):529-41.

49. Green DR. Overview: apoptotic signaling pathways in the immune system. Immunol Rev. 2003;193:5-9.

50. Kerr JF, Wyllie AH, Currie AR. Apoptosis: a basic biological phenomenon with wide-ranging implications in tissue kinetics. $\mathrm{Br} \mathrm{J}$ Cancer. 1972;26(4):239-57.

51. Wang J, Lenardo MJ. Roles of caspases in apoptosis, development, and cytokine maturation revealed by homozygous gene deficiencies. J Cell Sci. 2000;113(Pt 5)(Pt 5):753-7.

52. Payne TM, Molestina RE, Sinai AP. Inhibition of caspase activation and a requirement for NF-kappaB function in the Toxoplasma gondiimediated blockade of host apoptosis. J Cell Sci. 2003;116(Pt 21):4345-58.

53. Keller P, Schaumburg F, Fischer SF, Hacker G, Gross U, Luder CG. Direct inhibition of cytochrome c-induced caspase activation in vitro by Toxoplasma gondii reveals novel mechanisms of interference with host cell apoptosis. FEMS Microbiol Lett. 2006;258(2):312-9.

54. Goebel S, Luder CG, Gross U. Invasion by Toxoplasma gondii protects human-derived HL-60 cells from actinomycin D-induced apoptosis. Med Microbiol Immunol. 1999;187(4):221-6.

55. Nishikawa Y, Kawase O, Vielemeyer O, Suzuki H, Joiner KA, Xuan $\mathrm{X}$, et al. Toxoplasma gondii infection induces apoptosis in noninfected macrophages: role of nitric oxide and other soluble factors. Parasite Immunol. 2007;29(7):375-85. 